\title{
Total endovascular repair for acute type $B$ dissection in the setting of right aortic arch with aberrant left subclavian artery and Kommerell diverticulum
}

Hung-Lung Hsu, MD, ${ }^{a, b}$ Chun-Yang Huang, MD, ${ }^{a}$ and Jer-Shen Chen, MD ${ }^{a, b}$

See related commentary on pages 411-2.

Right aortic arch with aberrant origin of left subclavian artery and Kommerell diverticulum is an unusual congenital anomaly. Hybrid surgery, which includes arch debranching and aortic endografting, is the mainstay to treat the Kommerell diverticulum. ${ }^{1,2}$ When acute type $\mathrm{B}$ aortic dis-

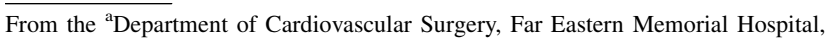
New Taipei City, Taiwan; and the ${ }^{\mathrm{b}}$ Faculty of Medicine, National Yang-Ming University School of Medicine, Taipei, Taiwan.

Disclosures: Authors have nothing to disclose with regard to commercial support. Received for publication Feb 11, 2015; revisions received March 24, 2015; accepted for publication April 3, 2015; available ahead of print May 1, 2015.

Address for reprints: Jer-Shen Chen, MD, Department of Cardiovascular Surgery, Far Eastern Memorial Hospital, 13F, No. 21, Section 2, Nan-Ya S Rd, Banqiao, New

Taipei City 220, Taiwan (E-mail: jershen@gmail.com).

J Thorac Cardiovasc Surg 2015;150:409-11

$0022-5223 / \$ 36.00$

Copyright (C) 2015 by The American Association for Thoracic Surgery http://dx.doi.org/10.1016/j.jtcvs.2015.04.007 section complicates the clinical picture, treatment is more difficult. Hybrid surgery had also been reported ${ }^{3}$ in this situation. To reduce the invasiveness of treatment even further, we report our method to treat this difficult situation in a totally endovascular approach.

A 47-year-old man came to the emergency department for acute tearing back pain. Acute type B aortic dissection was diagnosed on the basis of computed tomography. Right aortic arch and aberrant left subclavian artery with Kommerell diverticulum was also found (Figure 1, $A$ and $B$ ). The arch vessels arose in the following order: left common carotid artery, right common carotid artery, right subclavian artery, and then aberrant left subclavian artery. The major intimal tear was just below the level of the Kommerell diverticulum (Figure 1,D). Medical treatment was given initially with labetalol, nicardipine, and fentanyl infusions. Aggravation of abdominal discomfort was reported, however, and progressive abdominal distention was observed. Abdominal plain film radiography showed severe ileus, and metabolic acidosis ensued. Prolonged respiratory

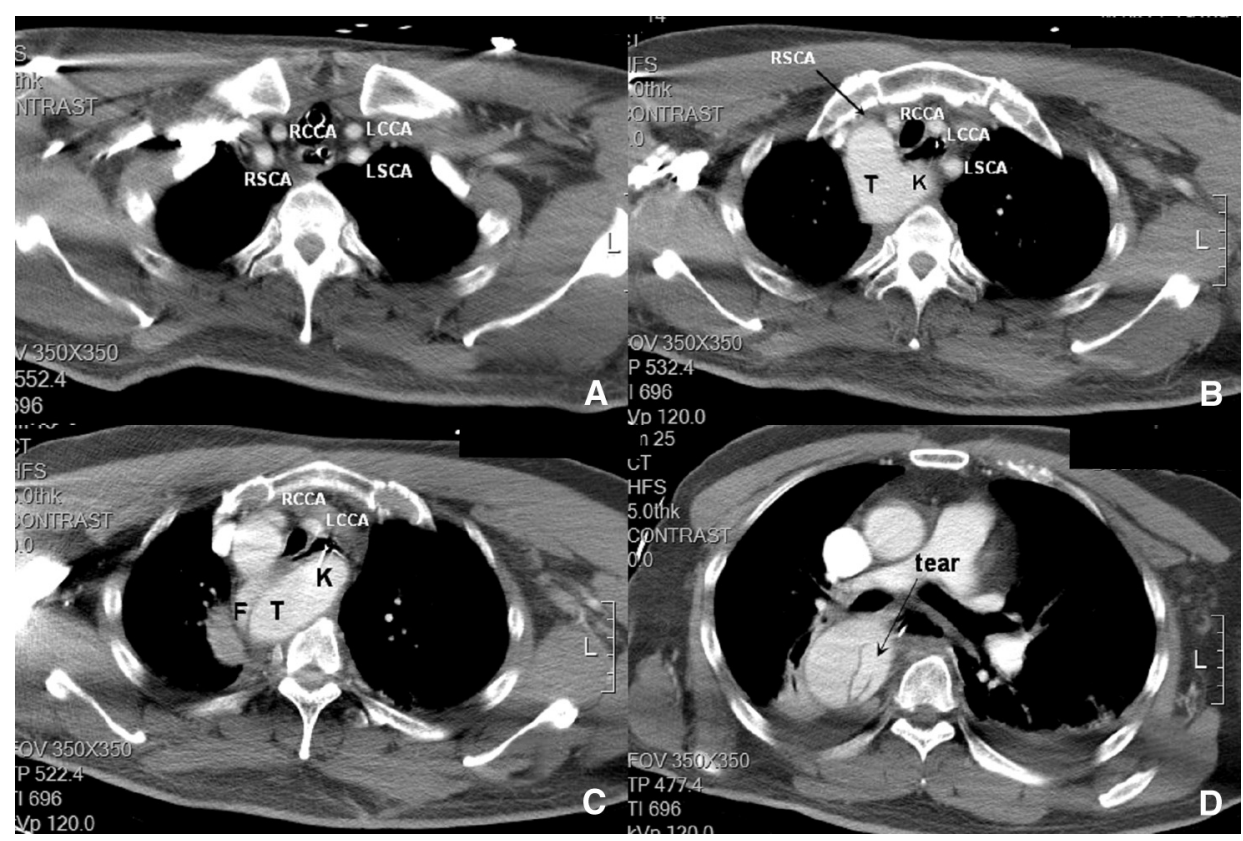

FIGURE 1. Preintervention computed tomography. The right aortic arch with aberrant left subclavian artery (LSCA) is shown. The first arch branch is the left common carotid artery ( $L C C A)$, the second arch branch is the right common carotid artery (RCCA), and the third branch is the right subclavian artery $(R S C A)(\mathrm{A})$. The left subclavian artery took off from the proximal descending aorta, with a Kommerell diverticulum $(K) \operatorname{larger}$ than $2 \mathrm{~cm}$ in diameter $(\mathrm{B}$ and C). The intimal tear was just below the level of the Kommerell diverticulum, and dissection extended upward to the level of the Kommerell diverticulum (C and D). $T$, True lumen; $F$, false lumen; $L$, left. 


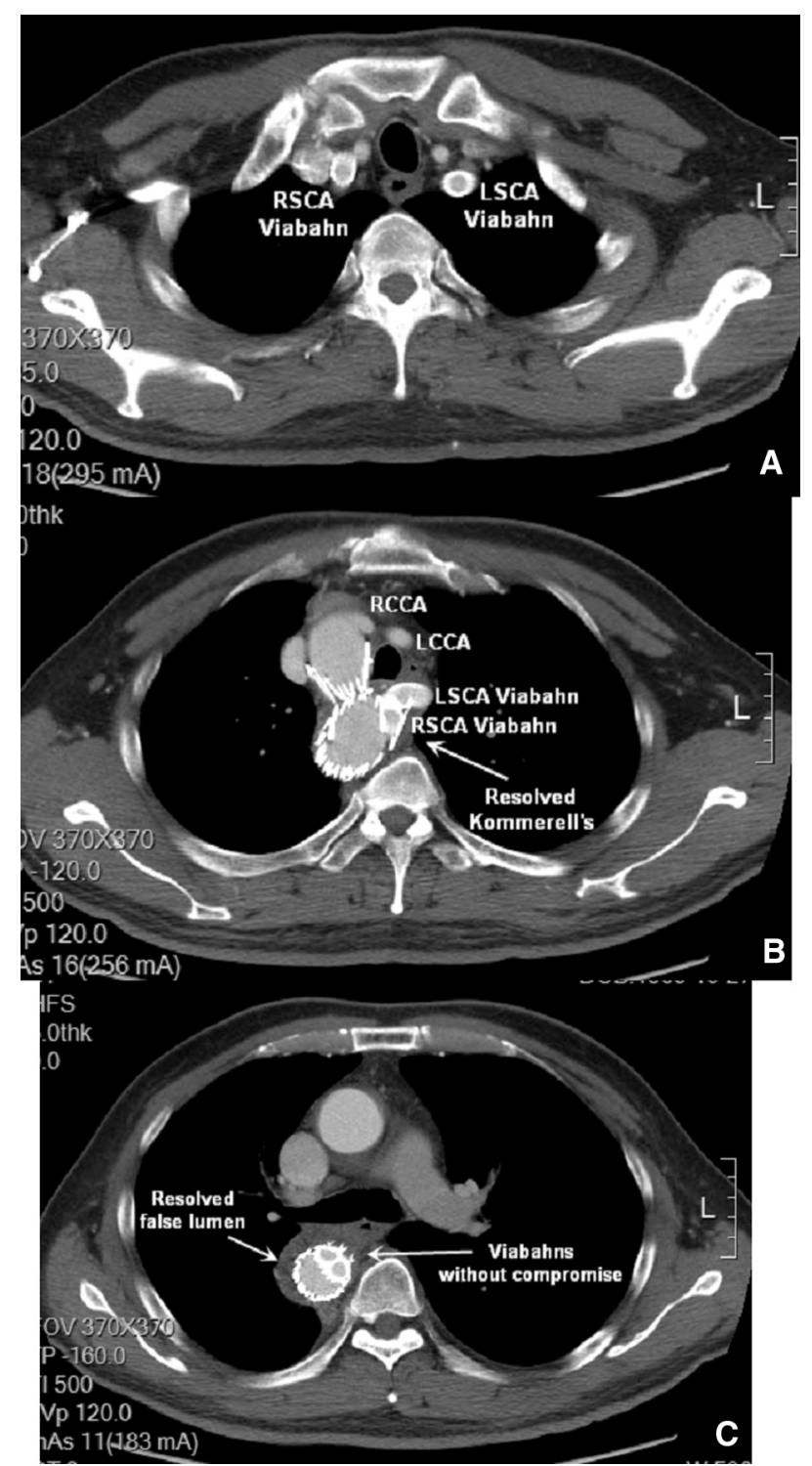

FIGURE 2. Postintervention computed tomography at 6-month follow-up. A, Patent Viabahn stent grafts in bilateral subclavian arteries can be seen. B, The Kommerell diverticulum has almost disappeared. C, The 2 Viabahn snorkel grafts went well in parallel in the descending aorta without any compromise. LSCA, Left subclavian artery; LCCA, left common carotid artery; $R C C A$, right common carotid artery; $R S C A$, right subclavian artery; $L$, left.

compensation for metabolic acidosis resulted in respiratory failure. Fever, tachycardia, and unstable blood pressure indicated systemic inflammatory response syndrome as a result of bowel ischemia. The patient was intubated about 36 hours after his initial presentation. Total endovascular repair of a complicated acute type B dissection, was arranged because of severe abdominal malperfusion.

The endovascular procedure was performed in the operation room with a portable C-arm (OEC 9800; GE Medical Systems, Salt Lake City, Utah). The patient's neck and both shoulders were also sterilized and draped. Bilateral carotid-subclavian bypass, subclavian artery embolization, and aortic endografting were our bailout procedures. The long-axis diameter of the true lumen at the lower thoracic aorta was approximately $25 \mathrm{~mm}$. To decrease the chance of stent graft-induced distal break, minimal oversizing of less than 5\% was adopted because the whole first aortic stent graft would be in the dissected aorta. A tapered 34 $\times 26 \times 156-\mathrm{mm}$ Zenith TX2 aortic stent graft (COOK Medical Incorporated, Bloomington, Ind) was deployed percutaneously below the midlevel of the Kommerell diverticulum through the right femoral artery after preloading 2 Perclose Proglide devices (Abbott Vascular, Santa Clara, Calif). Bilateral brachial arteries were exposed through elbow cutdowns, and $11 \mathrm{~F}$ sheaths were inserted in both sides. Two $10 \times 150$-mm Viabahn stent grafts (W.L. Gore and Associates Inc, Flagstaff, Ariz) were inserted into the Zenith TX2 aortic stent graft in the descending aorta through bilateral brachial arteries as "snorkel" grafts. The diameter of healthy proximal landing zone, between the right common carotid artery and the right subclavian artery, was $27 \mathrm{~mm}$. To conform to the snorkel grafts, a $30 \%$ oversizing was applied. A $36 \times 127$-mm Zenith TX2 aortic stent graft was deployed distal to the right common carotid artery. The intimal tear and Kommerell diverticulum were both excluded at the conclusion of the procedure.

After total endovascular repair, the patient's abdominal malperfusion improved promptly. He was extubated the next day and discharged 6 days later. Low-dose aspirin $(100 \mathrm{mg} / \mathrm{d})$ was given in addition to antihypertensive medications. Bilateral brachial artery pulsations were easily palpable. Blood pressures in all 4 extremities were equal. Six months later, follow-up computed tomography showed widely patent bilateral subclavian artery reversed chimney grafts (Figure 2, A). The Kommerell diverticulum was also well excluded from the arterial circulation and significantly reduced in size (Figure 2, B). The false lumen had also completely thrombosed (Figure 2, C). Three-dimensional reconstruction computed tomography is shown in Figure 3.

Our case demonstrates that it is feasible to repair such a complex lesion in a totally endovascular way, even in the setting of acute type B aortic dissection. The Zenith TX2 aortic stent grafts sealed the intimal tear of acute aortic dissection. Left subclavian artery Viabahn stent graft effectively excluded the Kommerell diverticulum. A right subclavian Viabahn stent graft was inserted because a secure proximal landing zone, which was between the right common carotid artery and the right subclavian artery in this patient, is quite important in the setting of acute aortic dissection. An insecure proximal landing zone could not have tolerated a $30 \%$ oversizing to conform to 2 subclavian artery stent grafts and might have led to proximal intimal break and even retrograde type A dissection, which would have been a disaster.

Although the procedure that we used is less invasive, it requires expert endovascular and open skills to perform. 


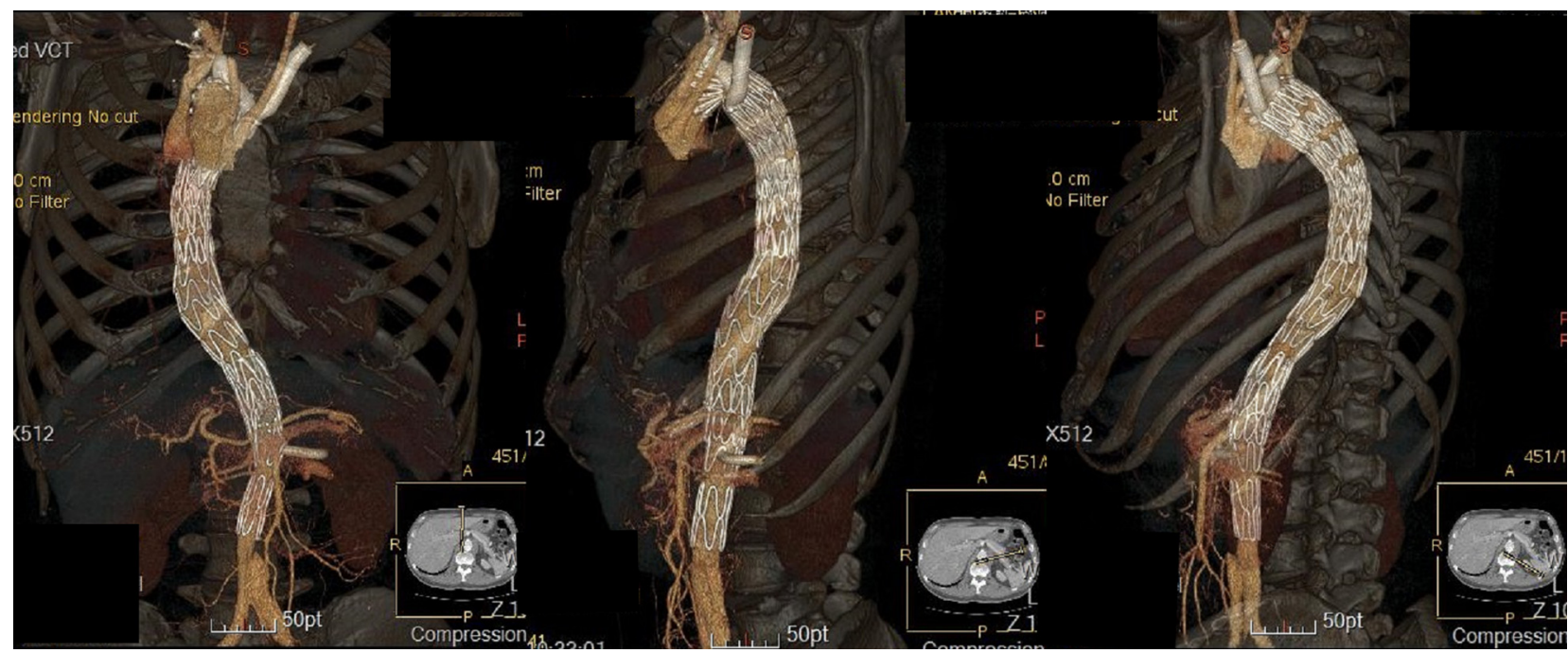

FIGURE 3. Three-dimensional reconstructed computed tomography in anteroposterior (left), lateral (center), and left posterior oblique (right) projections gives a clear overview of how the total endovascular repair was achieved.

Perfusion to both arms and vertebral arteries can be well preserved. These endovascular devices are usually available in an endovascular suite and do not need a custom-made process.

\section{DISCUSSION}

A Kommerell diverticulum that accompanies the aberrant left subclavian artery origin from right aortic arch usually expands with time. The risk of rupture and dissection increases with size expansion. In the endovascular era, arch debranching with aortic endografting is the mainstay of elective treatment for Kommerell diverticulum. ${ }^{1}$ When an acute type $\mathrm{B}$ dissection complicates this picture, however, especially in the presence of malperfusion, surgical risk rises. If we can make the operation completely endovascular, it might be better tolerated. Our method, which uses bilateral subclavian artery snorkels and aortic endografting, is less invasive, although it requires expert endovascular and open skills to perform. It does not need custom-made devices and is suitable for emergency settings.

\section{References}

1. Idrees J, Keshavamurthy S, Subramanian S, Clair DG, Svensson LG, Roselli EE. Hybrid repair of Kommerell diverticulum. J Thorac Cardiovasc Surg. 2014;147: 973-6.

2. Yamashiro S, Nagano T, Kuniyoshi Y, Kise Y, Maeda T, Arakaki R. Endovascular repair of intrathoracic ruptured Kommerell's diverticulum. Asian Cardiovasc Thorac Ann. 2012;20:587-90.

3. Higashi R, Matsumura Y, Yamaki F. A single stage hybrid repair of a complicated acute type B dissection with aortic arch involvement. Ann Vasc Dis. 2014;7:141-4.

\section{EDITORIAL COMMENTARY}

\section{Through the endovascular looking glass: Total endovascular repair for combined congenital and acute aortic arch disease}

\section{Grayson H. Wheatley III, MD}

\footnotetext{
From the Division of Cardiovascular Surgery, Temple University School of Medicine, Philadelphia, $\mathrm{Pa}$.

Disclosures: Authors have nothing to disclose with regard to commercial support. Received for publication April 7, 2015; accepted for publication April 9, 2015; available ahead of print May 8, 2015.

Address for reprints: Grayson H. Wheatley III, MD, Division of Cardiovascular Surgery, Temple University School of Medicine, 3401 N. Broad St, 3rd Floor, Zone C, Suite 301, Philadelphia, PA 19140 (E-mail: grayson.wheatley@tuhs.temple).

J Thorac Cardiovasc Surg 2015;150:411-2

$0022-5223 / \$ 36.00$

Copyright (c) 2015 by The American Association for Thoracic Surgery http://dx.doi.org/10.1016/j.jtcvs.2015.04.024
}

See related article on pages 409-11.

Through the lens of endovascular aortic techniques, new treatment horizons for a broad spectrum of aortic diseases are coming into better focus. Although endovascular therapies for zone 0 appear off in the distance and are still a bit hazy, total endovascular arch repair is becoming a more focused reality. ${ }^{1}$ As our understanding improves 